\title{
Damage formation and recovery in Fe implanted 6H-SiC
}

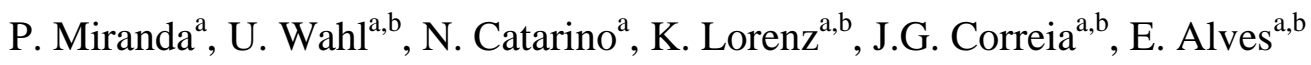 \\ a) Instituto Tecnológico e Nuclear, Estrada Nacional 10, 2686-953 Sacavém, Portugal \\ b) Centro de Física Nuclear de Universidade de Lisboa, 1649-003 Lisboa, Portugal
}

\begin{abstract}
Silicon carbide doped with magnetic ions such as Fe, Mn, Ni or Co could make this wide band gap semiconductor part of the diluted magnetic semiconductor family. In this study, we report the implantation of $6 \mathrm{H}-\mathrm{SiC}$ single crystals with magnetic ${ }^{56} \mathrm{Fe}^{+}$ions with an energy of $150 \mathrm{keV}$. The samples were implanted with $5 \times 10^{14} \mathrm{Fe}^{+} / \mathrm{cm}^{2}$ and $1 \times 10^{16} \mathrm{Fe}^{+} / \mathrm{cm}^{2}$ at different temperatures to study the damage formation and lattice site location. The samples were subsequently annealed up to $1500^{\circ} \mathrm{C}$ in vacuum in order to remove the implantation damage. The effect of the annealing was followed by Rutherford Backscattering/Channeling (RBS/C) measurements. The results show that samples implanted above the critical amorphization temperature reveal a high fraction of Fe incorporated into regular sites along the [0001] axis. After the annealing at $1000^{\circ} \mathrm{C}$, a maximum fraction of $75 \%$, corresponding to a total of $3.8 \times 10^{14} \mathrm{Fe}^{+} / \mathrm{cm}^{2}$, was measured in regular sites along the [0001] axis. A comparison is made between the observed annealing behavior and the one measured in low fluence $\left(2 \times 10^{13} \mathrm{~cm}^{-2}\right) \beta$ emission channeling experiments using the radioactive isotope ${ }^{59} \mathrm{Fe}\left(t_{1 / 2}=45 \mathrm{~d}\right)$, where the sample was implanted at room temperature and the $\beta^{-}$emission channeling yield was measured by means of a positionsensitive detector.
\end{abstract}

Keywords: 6H-SiC, Ion implantation, Damage annealing, Lattice sites, Emission channeling

* Corresponding author, e-mail: ealves@itn.pt

phone: ++351-21-9946086

\section{Introduction}

The quest for diluted magnetic semiconductor (DMS) materials is among the most intensively researched areas worldwide [1,2]. The possibility to use spin polarization to create new functionalities for electronics and photonics makes this field interesting for the semiconductor industry. Triggered by its unique properties for high power devices, during the last decade a considerable amount of work was also performed on possible applications of silicon carbide in spintronics $[3,4]$. To achieve this goal there are three major issues to solve: the material must be a ferromagnetic semiconductor, the value of the Curie temperature must be around room temperature (or above) and the matrix must remain a dilute solution instead of forming metal clusters or second phases. The availability of different SiC polytypes opens a great number of possibilities depending on the structure of the polytype. The magnetic properties of $\mathrm{SiC}$ doped with transition metals have been studied theoretically, and the results, although controversial in some cases, suggest the dependence of the magnetism on the site occupation of the metallic ions $[5,6]$. The interpretations of the experimental results, on the other hand, are complicated by the formation of new phases or clustering of the impurities which could be the origin of the magnetic properties $[7,8]$.

The low solubility of impurities in $\mathrm{SiC}$ poses a problem when we try to incorporate large amounts of magnetic dopants while keeping the structural integrity of the matrix. In any 
case, the need for a non-equilibrium technique like ion implantation is necessary to achieve the required concentrations. As a violent process, implantation creates damage and as a binary compound the defects in both sublattices ( $\mathrm{Si}$ and $\mathrm{C}$ ) raise a multitude of defect configurations that need to be annealed. The defect production and annealing of the different SiC polytypes was studied by several groups, and it is reasonably well understood [9-12]. The short range nature of the covalent bonds makes $\mathrm{SiC}$ very radiation sensitive and easy to amorphize, and temperatures above $1000^{\circ} \mathrm{C}$ are necessary to promote defect recovery. The recrystallization and stability of the implanted species in the lattice are key issues for the integration of the implantation technique in the doping process of $\mathrm{SiC}$ for spintronic applications.

\section{Experimental details}

$6 \mathrm{H}-\mathrm{SiC}$ single crystal samples were cut from a wafer obtained from CrysTec $\mathrm{GmbH}$ and implanted with $\mathrm{Fe}$ ions over the temperature range from 25 (RT) to $550^{\circ} \mathrm{C}$, with the beam tilted $10^{\circ}$ off the c-axis, an energy of $150 \mathrm{keV}$ and fluences of $5 \times 10^{14} \mathrm{Fe}^{+} / \mathrm{cm}^{2}$ and $1 \times 10^{16} \mathrm{Fe}^{+} / \mathrm{cm}^{2}$. According to SRIM [13], the Fe range is $83 \mathrm{~nm}$, which is slightly higher than the experimental value, $75 \mathrm{~nm}$. The control of the fluence was obtained by integration of the beam current, kept below $0.5 \mu \mathrm{A} / \mathrm{cm}^{2}$ to avoid dose rate effects [14]. Some selected samples were further rapid thermal annealed (RTA) at $1000^{\circ} \mathrm{C}$ and $1500^{\circ} \mathrm{C}$ for $30 \mathrm{~s}$ at a pressure of $5 \times 10^{-4} \mathrm{~Pa}$. The crystalline quality and structural properties of the samples were characterized by RBS/C. A collimated $2 \mathrm{MeV} \mathrm{He}^{+}$beam delivered by a Van de Graaff accelerator was used as analyzing beam in order to determine the implantation and damage profiles of the samples. Channeling measurements were done along the [0001] axes to inspect the displaced atoms. The lattice site location of the Fe ions along the [0001] atomic rows was performed by detailed angular scans. For the emission channeling experiments, the radioactive isotope ${ }^{59} \mathrm{Fe}\left(t_{1 / 2}=45 \mathrm{~d}\right)$ was produced and implanted at low fluence $\left(2 \times 10^{13} \mathrm{~cm}^{-2}\right)$ into a $6 \mathrm{H}-\mathrm{SiC}$ single crystal with $60 \mathrm{keV}$ $10^{\circ}$ off the surface normal at CERN's ISOLDE facility. The angular-dependent count rate of the emitted $\beta^{-}$particles in the energy range $50-461 \mathrm{keV}$ was then measured using a $3 \times 3 \mathrm{~cm}^{2}$ position-sensitive $\mathrm{Si}$ pad detector of $22 \times 22$ pixels placed at $29 \mathrm{~cm}$ from the sample.

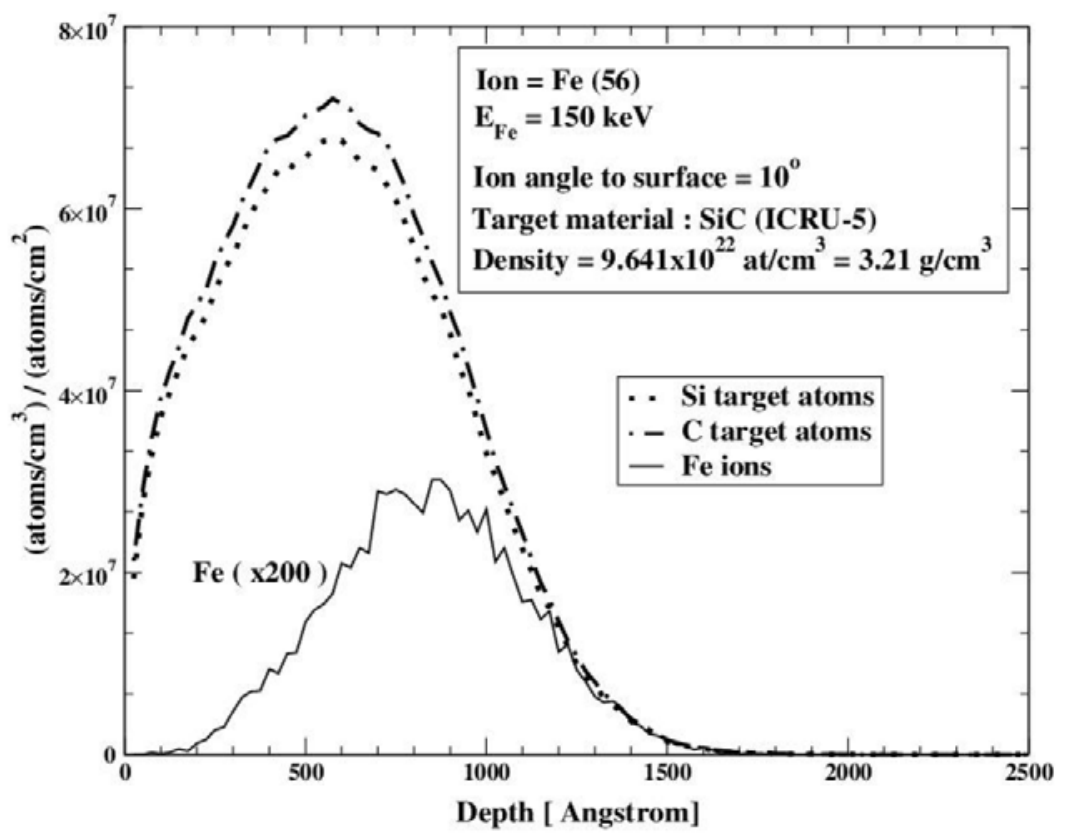

Fig. 1: Recoils and Fe implantation profile obtained with SRIM code. Despite the different mass and displacement energies, the recoil profiles differ only in the total number of $\mathrm{C}$ and $\mathrm{Si}$ recoils. 


\section{Results and discussion}

\subsection{Structural analysis}

The $6 \mathrm{H}-\mathrm{SiC}$ single crystals are very radiation sensitive and became amorphous at very low implantation fluences. The predicted SRIM recoils and Fe profiles are displayed in Fig. 1. The $\mathrm{Si}$ and $\mathrm{C}$ recoil profiles nearly overlap despite the different mass and displacement energies used in the simulation, $20 \mathrm{eV}$ for $\mathrm{C}$ and $35 \mathrm{eV}$ for Si respectively [15]. The presence of $\mathrm{C}$ and Si displaced atoms at close distances favors the recrystallization process, despite the imbalance of the total number of recoils predicted by the SRIM results. At room temperature, the amorphous transformation is already observed for the lowest implanted fluence, $5 \times 10^{14} \mathrm{Fe}^{+} / \mathrm{cm}^{2}$, as indicated by the overlap of the random and aligned spectra through the entire implanted region ( $150 \mathrm{~nm}$ ) shown in Fig. 2. Damage accumulation in the SiC polytypes under irradiation has been explained by several models based on the direct impact mechanism $[16,17]$.

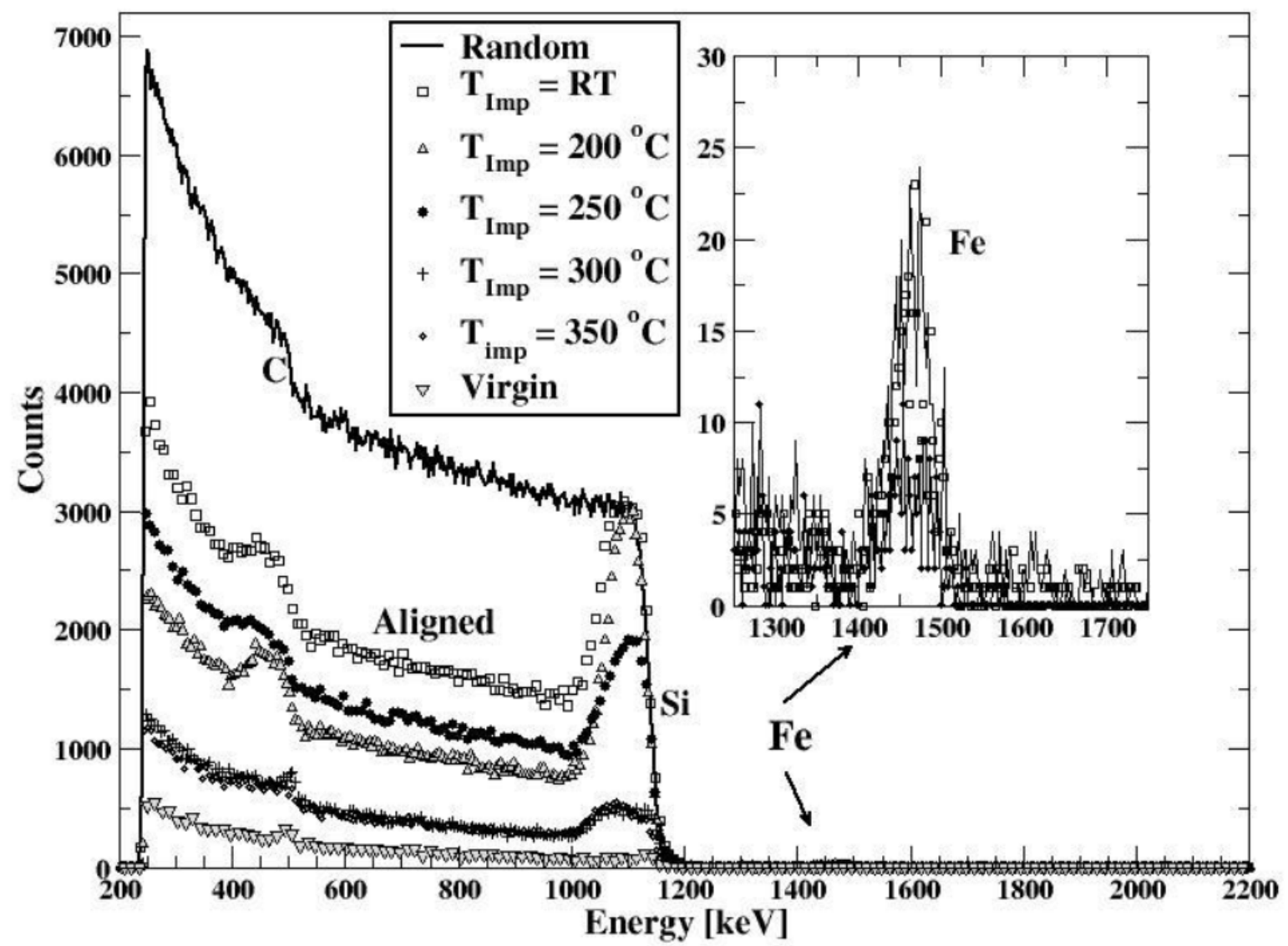

Fig. 2: Random and [0001] aligned RBS spectra from 6H-SiC implanted with a nominal fluence of $5 \times 10^{14} \mathrm{Fe}^{+} / \mathrm{cm}^{2}$ at different temperatures.

In the model proposed by Jagielski et al. [17] a multi step accumulation of the damage (MSDA) is considered. The model reproduces quite well the results obtained by Debelle et al. [12] for a $100 \mathrm{keV}$ implantation, and an amorphization threshold of $0.45 \mathrm{dpa}$ was established for $6 \mathrm{H}-\mathrm{SiC}$. Here, the displacements per atom are around $0.7 \mathrm{dpa}$, and the implanted region is rendered amorphous for all the implantations at RT. The increase of the implantation temperature promotes the annealing of the defects, inhibiting the amorphization. At $200^{\circ} \mathrm{C}$ the width of the amorphous layer is reduced, and above $300^{\circ} \mathrm{C}$ the samples remain crystalline with 
some residual damage distributed over the implanted region. The results are summarized in Fig. 3 where we plot the evolution of the difference of the minimum yield $\Delta \chi_{\text {min }}$ ( $\Delta \chi_{\text {min }}={ }^{I m p} \chi_{\text {min }}-{ }^{\text {Vir }} \chi_{\text {min }}$, the difference of minimum yields for the virgin and implanted samples at the same depth) with the temperature. From the curve, we could estimate a value of $250^{\circ} \mathrm{C}$ for the critical temperature above which the amophization is prevented in $\mathrm{SiC}$, which is very similar to the value (around $230^{\circ} \mathrm{C}$ ) found by Weber et al. [11]. We have implanted fluences as high as $1 \times 10^{16} \mathrm{Fe}^{+} / \mathrm{cm}^{2}$ at $350^{\circ} \mathrm{C}$ and only a buried damage region developed at the depth of the implanted ions. The nature of the damage could not be determined with RBS/C, but other studies in similar conditions show the presence of dislocations and localized amorphous zones in the implanted region [10,11]. Recently Wendler et al. [18] showed the presence of different mechanisms for defect annealing during the implantation above $200^{\circ} \mathrm{C}$. The mobility of point defects, vacancies mostly, play a major role in defect annihilation up to $350^{\circ} \mathrm{C}$ in the low fluence implantation regime. For high fluences, the role of the implanted species must be considered, and we could not rule out the formation of other phases (iron silicides) during the implantation. In our study, the XRD results (not shown) did not reveal any evidence for the presence of other phases, but the interaction volume could not be sufficient to produce a measurable signal.

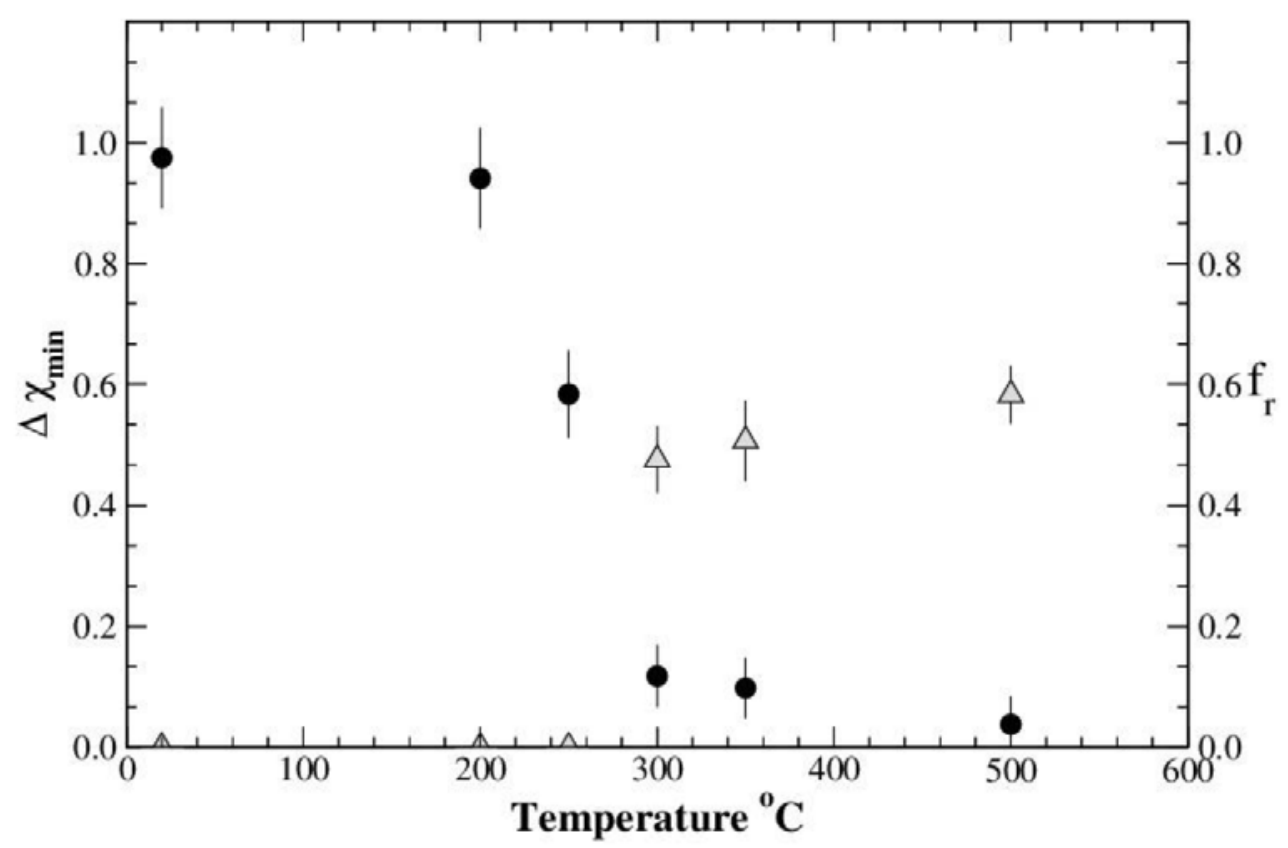

Fig. 3: Evolution of the damage (circles) with the implantation temperature in the Si sublattice at the implanted depth according to the results of Fig. 2. The regular fraction of Fe (triangles), fr, is also shown on the right axis, as explained in the text.

The recovery of the damage is an important step in all the implantation processes. The presence of different chemical species and defect concentrations makes the recrystallization process in SiC difficult. The evolution of the amorphous layer with annealing temperature is shown in Fig. 4. A layer by layer recrystallization starting at the amorphous/crystalline interface explains the decrease of the thickness of the original amorphous layer at $1000^{\circ} \mathrm{C}$. A value of $1.7 \mathrm{~nm} / \mathrm{s}$ was estimated for the regrowth velocity at this temperature. The annealing at $1500^{\circ} \mathrm{C}$ promotes the complete recrystallization of the amorphous layer. The higher value of the minimum yield after the annealing is due to some residual damage at the surface that gives rise to the $\mathrm{C}$ and $\mathrm{Si}$ surface peaks observed in the aligned spectrum. What is more surprising is the retention of the implanted Fe in the crystal. In the literature, different groups reported that 
at this high temperature the implanted species out-diffuse and are lost through the surface $[10,19]$. Our results show the redistribution of the Fe, but a significant fraction is incorporated into the recrystallized lattice suggesting the possibility to achieve the full activation of the $\mathrm{Fe}$ ions in $6 \mathrm{H}-\mathrm{SiC}$.

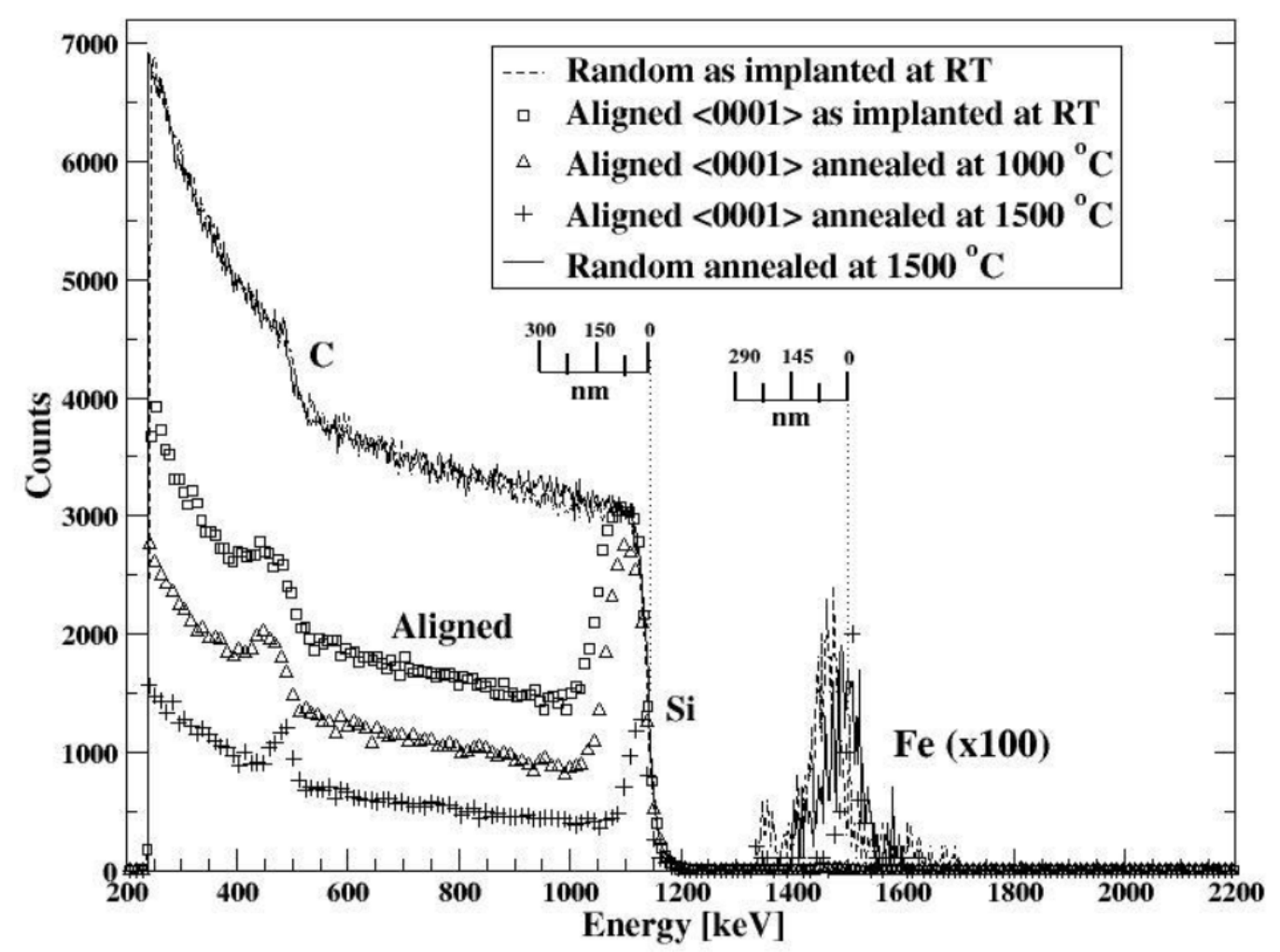

Fig. 4: Random and [0001] aligned spectra showing the recrystallization of the amorphous layer of the sample implanted at room temperature with $5 \times 10^{14} \mathrm{Fe}^{+} / \mathrm{cm}^{2}$. Despite the $\mathrm{Fe}$ redistribution the total amount was conserved.

\subsection{Site location}

An important aspect of the incorporation of impurities in materials is the site location. The comparison of the random and aligned yield of Fe indicates the incorporation of a large fraction into regular sites. The maximum regular fraction $f_{\mathrm{r}}$ of $\operatorname{Fe}\left(f_{\mathrm{r}}=1-{ }^{\mathrm{Fe}} \chi_{\text {min }} / 1-{ }^{\mathrm{Si}} \chi_{\text {min }}\right)$ introduced in lattice sites along the [0001] axis during the implantation was $60 \%$, which was obtained for the sample implanted at $500^{\circ} \mathrm{C}$. To obtain a more precise information about the position of the Fe ions, we performed detailed angular scan through the [0001] direction. The results obtained after the implantation and annealing at $1000^{\circ} \mathrm{C}$ for the sample implanted with $5 \times 10^{14} \mathrm{Fe}^{+} / \mathrm{cm}^{2}$ are shown in Fig. 5. The regular fraction increases from $45 \%$ to about $75 \%$. However, it is evident that the Fe curve is narrower than the $\mathrm{Si}$, which is an indication that the ions were not occupying a pure substitutional site in the Si sublattice. In addition, we obtained first results with very low fluences of implanted Fe by means of $\beta^{-}$emission channeling from radioactive ${ }^{59} \mathrm{Fe}$, where the influence of the implantation damage is very small. For that purpose $2 \times 10^{13} \mathrm{~cm}^{-2}$ of $60 \mathrm{keV}{ }^{59} \mathrm{Fe}$ ions was implanted at room temperature, and the $\beta^{-}$ emission yield measured around the major crystallographic directions by means of a positionsensitive detector [20]. Fig. 6 shows the emission channeling pattern along the $c$-axis in the asimplanted state. The clear channeling effects of the axial [0001] and the family of planar (11-20) directions show that a considerable fraction of the Fe probes are located in sites that are aligned with the mixed rows of $\mathrm{Si}$ and $\mathrm{C}$ atoms. A preliminary analysis by means of 
comparing to many-beam simulations of electron emission channeling gave two interesting results. First, the absence of electron channeling effects along the family of $(-1100)$ planes for substitutional emitter atoms seems to be a characteristic of the $6 \mathrm{H}$ structure; second, the pattern is well compatible with a significant fraction of emitter atoms being located on interstitial sites displaced from the $c$-axis.

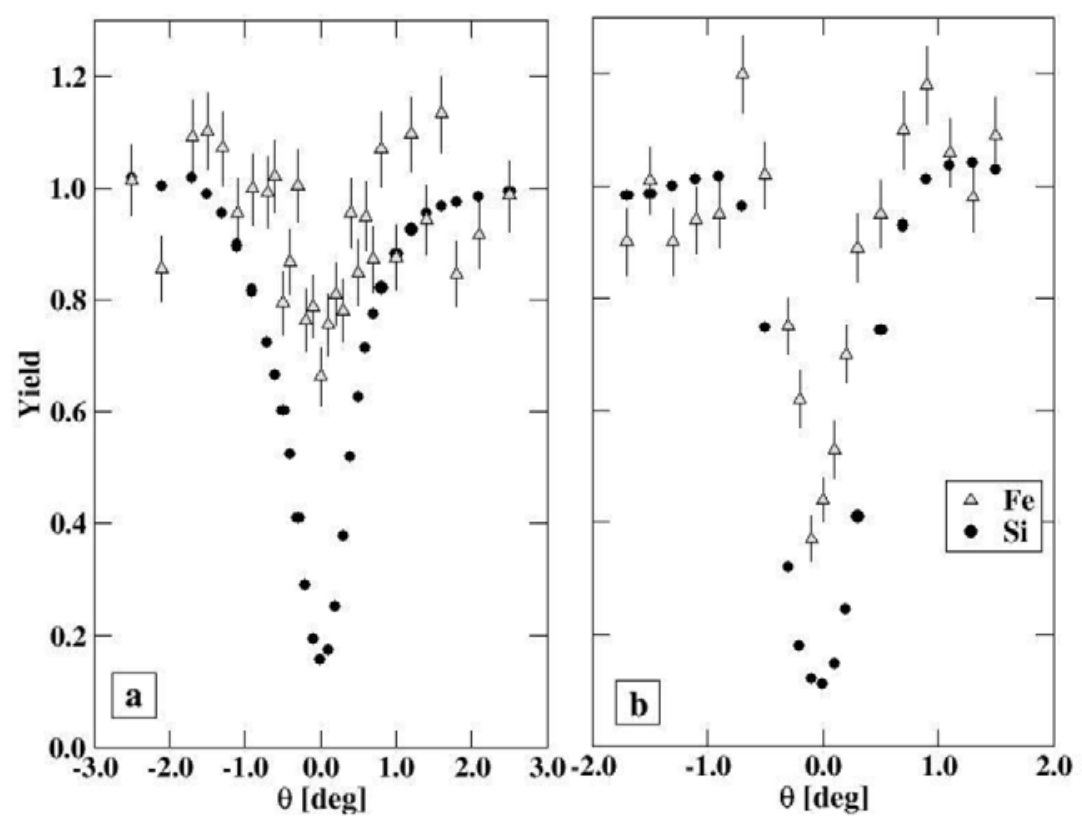

Fig. 5: Angular scan through the [0001] axis after implantation (a) and annealing at $1000^{\circ} \mathrm{C}$ (b) for the samples implanted at $350^{\circ} \mathrm{C}$ with $5 \times 10^{14} \mathrm{Fe}^{+} / \mathrm{cm}^{2}$.

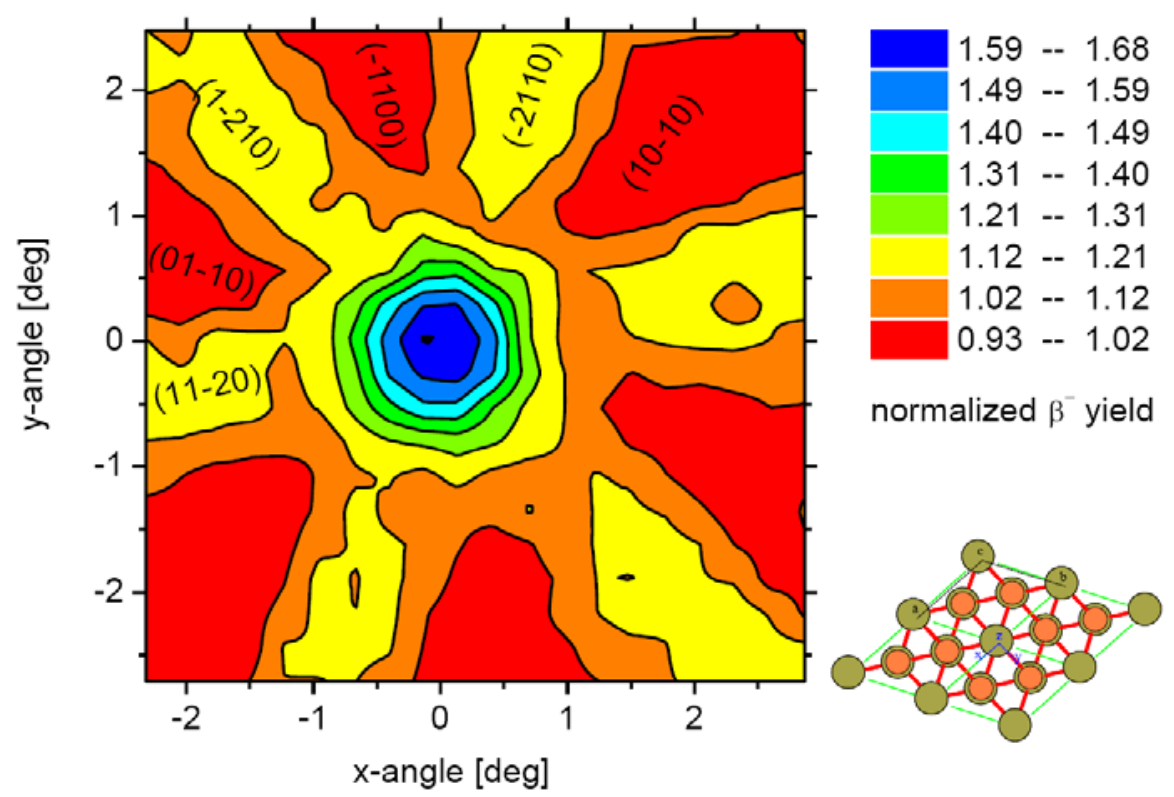

Fig. 6: Normalized $\beta^{-}$emission yield around the [0001] direction of a ${ }^{59} \mathrm{Fe}$ implanted $6 \mathrm{H}-\mathrm{SiC}$ crystal. The inset in the lower right hand corner shows the orientation of the crystal during the measurement.

To obtain a precise lattice site location of the Fe ions in the $6 \mathrm{H}$-SiC structure we need to perform more detailed RBS/C angular scans through tilted axial directions and compare all data to the results of Monte Carlo simulations. Similarly, for the emission channeling 
experiments the patterns need to be fully analyzed by fitting to the results of many-beam simulations. Due to the large number of available sites in the lattice, this is a complex task and the results will be published in an independent paper.

\section{Conclusions}

The introduction of $\mathrm{Fe}$ ions into $6 \mathrm{H}-\mathrm{SiC}$ regular lattice sites using ion implantation was successfully achieved. The amorphization is avoided by implanting at temperatures above $250^{\circ} \mathrm{C}$. For the samples implanted at lower temperatures, the amorphous layer regrows epitaxially at $1500^{\circ} \mathrm{C}$. The recrystallization induces the redistribution of the $\mathrm{Fe}$ ions in the implanted region with some segregation towards the surface, but the total amount of $\mathrm{Fe}$ is conserved. The samples implanted above the critical amorphization temperature show a high fraction of Fe incorporated into regular sites along the [0001] axis. After the annealing at $1000^{\circ} \mathrm{C}$, a maximum fraction of $75 \%$, corresponding to a total of $3.8 \times 10^{14} \mathrm{Fe}^{+} / \mathrm{cm}^{2}$, was measured in regular sites along the [0001] axis.

\section{Acknowledgments}

We acknowledge financial support from the Portuguese Foundation for Science and Technology through CERN/FP/116320/2010 and PTDC/CTM/100756/2008 as well as the SPIRIT project, EC Grant agreement No. 227012-CP-CSA-Intra. The authors also thank the assistance of S. Miranda during the RTA and J. Rocha for the implantations.

\section{References}

[1] S.J. Pearton, C. R Abernathy, D.P. Norton, A.F. Hebard, Y.D. Park, L.A. Boatner, J.D. Budai, Mater. Science Eng. R40 (2003) 37.

[2] T. Dietl, H. Ohno, F. Matsukara, J. Cibert, D. Ferrand, Science 287 (2000) 1019.

[3] N. Theodoropoulou, A.F. Hebard, S.N.G. Chu, M.E. Overberg, C.R. Abernathy, S.J. Pearton, R.G. Wilson, J.M. Zavada, Y.D. Park, J. Vac. Sci. Tech. A 20 (2002) 579.

[4] H. Pan, Y.W. Zhang, V. Shenoy, H. Gao, Appl. Phys. Lett. 96 (2010) 192510.

[5] M.S. Miao, W.R.L. Lambrecht, Phys. Rev. B 68 (2003) 125204.

[6] A. Los, V. Los, J. Phys.: Condens. Matter 21 (2009) 206004.

[7] F. Takano, W. Wang, H. Akinaga, H. Ofuchi, S. Hishiki, T. Ohshima, J. Appl. Phys. 101 (2007) $09 N 510$.

[8] C. Dupeyrat, A. Declémy, M. Drouet, D. Eyidi, L. Thomé, A. Debelle, M. Viret, F. Ott, Physica B 404 (2009) 4731.

[9] W.J. Weber, W. Jiang, F. Gao, R. Devanathan, Nucl. Instrum. Meth. B 190 (2002) 261.

[10] E. Wendler, A. Heft, W. Wesch, Nucl. Instrum. Meth. B 141 (1998) 105.

[11] W.J. Weber, L.M. Wang, N. Yu, N.J. Hess, Mat. Science and Eng. A253 (1998) 62.

[12] A. Debelle, L. Thomé, D. Dompoint, A. Boulle, F. Garrido, J. Jagielski, D. Chaussende, J. Phys. D: Appl. Phys. 43 (2010) 455408.

[13] J. F. Ziegler, J. P. Biersack, U. Littmark, The stopping and ranges of ions in matter, Pergamon Press, New York, 2003; www.srim.org.

[14] Y. Zhang, W.J. Weber, W. Jiang, C.M. Wang, A. Hallen, G. Possnert, J. Appl. Phys. 93 (2003) 1954.

[15] R. Devanathan, W.J. Weber, F. Gao, J. Appl. Phys. 90 (2001) 2303.

[16] W.J. Weber, Nucl. Instrum. Meth. B166-167 (2000) 98.

[17] J. Jagielski, L. Thomé, Appl. Phys. A: Mat. Sci. Process 97 (2009) 147.

[18] E. Wendler, Th. Bierschenk, W. Wesch, E. Friedland, J.B. Malherbe, Nucl. Instrum. Meth. B 268 (2010) 2996.

[19] A. Kozanecki, C. Jeynes, B.J. Sealy, A. Nejim, Nucl. Instrum. Meth. B136-138 (1998) 1272.

[20] U. Wahl, J.G. Correia, A. Czermak, S.G. Jahn, P. Jalocha, J.G. Marques, A. Rudge, F. Schopper, J.C. Soares, A. Vantomme, P. Weilhammer, The ISOLDE collaboration, Nucl. Instr. Meth. A 524 (2004) 245. 